\title{
"Movilizados" de Malvinas en Chaco y Corrientes. Las luchas por reconocimiento en clave comparativa
}

\author{
"Mobilized" to Malvinas in Chaco and Corrientes. The fights for \\ recognition in comparative perspective
}

\section{Daniel Chao *}

* CONICET - Universidad Nacional del Nordeste. Instituto de Investigaciones Geohistóricas, Argentina | I.daniel.chao@gmail.com

\section{PALABRAS CLAVE}

Guerra de Malvinas

Movilizados

Veteranos

Reconocimiento

\section{KEYWORDS}

Malvinas War

Mobilized

Veterans

Recognition

\section{RESUMEN}

En este artículo analizo dos casos provinciales -en Chaco y Corrientes- de luchas de colectivos de ex soldados movilizados para ser reconocidos por las legislaciones locales como veteranos de la guerra de Malvinas. Propongo abordar en clave comparativa los procesos de presentaciones de proyectos de ley para pensiones y reconocimiento histórico y moral que estuvieron acompañados por acciones de protesta en el espacio público entre 2006 y 2011. Divido el análisis en tres dimensiones (identitaria, estratégica-legal y estratégica-política) atendiendo a la relación entre Estado subnacional, movimientos sociales intervinientes y el problema del reconocimiento. Concluyo dando cuenta que la veteranía de los movilizados lejos está de resolverse y que los grados de reconocimiento estatal locales dependen de la complejidad de la red de relaciones políticas involucradas en cada caso. 


\section{Introducción}

Entre mayo y julio de 2015 la Corte Suprema de Justicia de la Nación (CSJN) argentina se expidió respecto a dos presentaciones referentes a demandas de ex soldados sobre su participación en la guerra de Malvinas. En primer término, el 19 de mayo de 2015, la CSJN reconoció como veterano de guerra al suboficial retirado de la Marina, Carmelo Antonio Gerez (R), con lo cual le otorgó el derecho a cobrar la pensión vitalicia y obtener todas las protecciones sociales del Estado hacia ese grupo. El punto de conflicto en este caso fue que Gerez no entró efectivamente en combate sino que cumplió funciones en la base naval de Puerto Belgrano, Punta Alta, partido de Coronel Rosales. Luego del hundimiento del ARA Gral. Belgrano, fue trasladado a la base de Río Grande en Tierra del Fuego y de allí se erigió como contralor de aviones nacionales y enemigos vía radar. Dos meses después del fallo, el 7 de julio de 2015, la Corte se volvió a expedir pero esta vez rechazando una demanda colectiva de un grupo de movilizados 1 a Comodoro Rivadavia durante el conflicto, quienes también solicitaban ser reconocidos como veteranos de guerra en el caso denominado “Arfinetti, Víctor Hugo c/Estado Nacional - Ministerio de Defensa - Ejército Argentino y otros s/Acción declarativa de certeza”. Los jueces en este caso aludieron directamente al problema de la participación en la acción bélica, que según el decreto 509/88 que reglamenta la ley 23.109 (beneficios a ex soldados conscriptos que han participado en las acciones bélicas desarrolladas en el Atlántico Sur entre el 2 de abril y el 14 de junio de 1982) es el único argumento para ser beneficiario del derecho.

Estos dos ejemplos son la muestra de un problema que atraviesa la actualidad de la posguerra de Malvinas: quién es -para el Estado- veterano de guerra 2 . En este trabajo traeremos dos casos provinciales -en Chaco y Corrientes- de luchas de colectivos de ex soldados para ser reconocidos por las legislaciones locales en tanto que partícipes de la guerra. Estos pedidos tienen la particularidad de estar encabezados por ex conscriptos que estuvieron bajo bandera $\underline{3}$ entre el 2 de abril y el 14 de junio de 1982, pero que no participaron en acciones de guerra concretas frente a los ingleses. Estos colectivos adscriben a varias definiciones: combatientes continentales, bajo bandera, convocados o movilizados; pero los une su exclusión al reconocimiento estatal a nivel nacional ${ }^{4}$. La propuesta en las siguientes líneas es comparar dos casos de presentaciones de proyectos de ley para pensiones y reconocimiento histórico y moral de movilizados, que estuvieron acompañados de acciones de protesta en el espacio público por parte de movimientos de ex soldados a nivel subnacional, en las ciudades de Corrientes y Resistencia. La elección de los casos no es sólo por proximidad geográfica (ambas ciudades están separadas por un puente) y temporal (el primer proyecto correntino se presentó en 2006, mientras que en Chaco fue en 2008), también en ambas latitudes los movimientos compartieron actividades en conjunto (tanto los interesados como de quienes los rechazaron) y fundamentalmente porque en la provincia de Chaco se logró reglamentar leyes de reconocimiento mientras que en Corrientes no. En este sentido, nos centramos en el aspecto legislativo y las luchas por obtener esas leyes porque entendemos que este es un modo potente para poner en relación al Estado, los movimientos sociales y el problema del reconocimiento.

Nos interesa la perspectiva comparada puesto que nos permite trabajar semejanzas y diferencias en diferentes acciones de movimientos sociales y su relación con lo institucional (Iglesias, 2008), lo cual puede hacer visible algunos marcos de explicación respecto al problema entre el 
reconocimiento estatal y las estrategias de los grupos sociales por alcanzarlo. Por esta razón en este estudio iniciaremos con un breve estado general del problema movilizado a nivel nacional (remarcando sus fundamentos y su actual judicialización) y luego haremos la comparación entre los casos señalados a partir de tres dimensiones: una dimensión identitaria del problema, otra estratégica-legal y la tercera estratégica-política. Trataremos de comprender las dinámicas y tensiones en cada caso, atendiendo a las disputas internas, externas y los fundamentos del reclamo.

En la primera de las dimensiones trabajaremos los sostenes de reconocimiento, los fundamentos para el pedido que presentan las asociaciones y las características preliminares delos movimientos que intervinieron en cada caso. En la dimensión estratégica-legal, compararemos los proyectos presentados, el papel de los movimientos durante el tratamiento, y sus resultados, es decir el derrotero del/los proyecto/s. Por último, respecto de la dimensión estratégica-política, nos interesa desarrollar las acciones de los movimientos de ex soldados movilizados en el espacio público, las relaciones y reacciones de los excombatientes (es decir los actualmente reconocidos por la ley), y las relaciones y reacciones de legisladores y miembros del Ejecutivo provincial. Nuestras fuentes serán documentos legales (leyes, decretos, resoluciones, proyectos de ley y expedientes con versiones taquigráficas de debates en las cámaras) y declaraciones públicas en medios gráficos y digitales locales. Cabe destacar que la idea de estrategia será entendida desde Bourdieu, no como un cálculo racional y sujeto siempre a fines de las acciones colectivas, sino como un desarrollo activo de líneas objetivamente orientadas que obedecen a regularidades y son explicables dando cuenta de las condiciones sociales. Es decir, la noción de estrategia (y las de identidades, puesto que el autor las entiende como una marca posible de estrategias (Bourdieu, 2013) $)^{\frac{5}{5}}$ nos permite ver la puesta en práctica de acciones de los movimientos de excombatientes ante ese espacio parcialmente objetivado que es el reconocimiento del Estado. Este punto de vista es lo que admite entender por qué los agentes actúan "racionalmente", con un sentido práctico sobre qué hacer frente a determinadas coyunturas (Bourdieu y Wacquant, 2014), aunque no siempre se alcancen los objetivos propuestos.

\section{El problema de los movilizados}

La ciudad de Rafaela, en la provincia de Santa Fe, fue sede del "Primer Congreso Nacional de Veteranos de Guerra de Malvinas afectados a las bases continentales” llevado a cabo el 10 y 11 de febrero de 2007. El espacio recibió a las organizaciones de ex soldados "que fueron destinados como Tropas de Apoyo de Combate, y/o permanecieron desarrollando efectivas acciones bélicas en las Bases del país”ㅌ․ El encuentro es la concreción nacional de diversos reclamos locales, que además impulsaron por diversas vías el reconocimiento estatal. Entre 2005 y 2010 se sucedieron un

número importante de proyectos de ley que intentaron atender al problema del sector ${ }^{7}$, los cuales muestran que el conflicto de los movilizados se concretó en numerosas acciones de Estado que quedaron truncas. En líneas generales el pedido de reconocimiento tiene tres sustentos; a) cierta inscripción a la experiencia de guerra traducida en sufrimiento, muertos e historia de combates; b) la ubicación de la guerra de Malvinas en el gran teatro de los conflictos bélicos internacionales; y c) una discusión sobre la especificidad de la amplitud de los Teatros de Operaciones, sobre todo poniendo de manifiesto la inexactitud de la distinción militar entre T.O.M. (Teatro de Operaciones 
Malvinas), T.O.A.S. (Teatro de Operaciones del Atlántico Sur) y T.O.S. (Teatro de Operaciones Sur).

Respecto a la experiencia de guerra $^{-}$, quienes reivindican el accionar de los soldados en el continente afirman que luego del 2 y 3 de abril, las primeras bajas de Malvinas se dieron cerca de la ciudad de Caleta Olivia, en la provincia de Santa Cruz, ante la amenaza de una invasión inglesa. Las diez bajas pertenecerían a una misión de combate a partir de la caída del helicóptero AE419 el día 30 de abril, dos días antes del hundimiento del ARA Gral. Belgrano, ante la invasión de un grupo de elite británico al continente argentino. A su vez, algunas historias de la guerra hablan de un intento de invasión a Tierra del Fuego, en lo que se habría denominado Operación MIKADO que tenía como objetivo la toma de la ciudad de Río Grande (Muñoz, 2005) ${ }^{9}$. La coincidencia de ambas memorias de guerra es que se llevaron a cabo fuera de las Islas Malvinas.

Otro de los argumentos esgrimidos por los movilizados para sustentar su pedido es la inscripción de la guerra de Malvinas en el terreno de la legislación bélica internacional. Particularmente se sostienen en el Protocolo I adicional a los Convenios de Ginebra de 1949 relativo a la protección de las víctimas de los conflictos armados internacionalesde1977. Este texto, firmado en agosto de 1977, pero que fue Ley para Argentina con la reforma de la constitución en 1994, establece en su Título III ("Métodos y medios de guerra. Estatuto de combatiente y de prisionero de guerra"), Sección II (Estatuto de combatiente y de prisionero de guerra), Artículo 43 respecto a las Fuerzas armadas:

Los miembros de las fuerzas armadas de una Parte en conflicto (salvo aquellos que formen parte del personal sanitario y religioso a que se refiere el artículo 33 del III Convenio) son combatientes, es decir, tienen derecho a participar directamente en las hostilidades $\underline{10}$.

Este es un fuerte argumento jurídico utilizado en los pedidos de reconocimiento, al que se le suma la especificidad de los Teatros de Operaciones. En relación a esto Andrea Rodriguez afirma que

[e]stas jurisdicciones no son un dato menor, ya que según sus límites varía la cantidad de veteranos reconocidos. Lo relevante (...) es que la legislación argentina considera que el TOM estuvo vigente desde el 2 de abril hasta el 7 de abril de 1982, y abarcó las Islas Malvinas, Georgias y Sándwich del Sur, y espacios marítimos y aéreos correspondientes, y que el TOAS, vigente desde el 7 de abril hasta el 14 de junio de 1982, incluía la Plataforma Continental, Islas Malvinas, Georgias, Sándwich del Sur y el espacio aéreo y submarino correspondiente (...). Además, en 1982 también se creó el Teatro de Operaciones Sur (TOS), que abarcaba la Patagonia al sur del paralelo 42, donde estuvieron movilizadas tropas que no fueron trasladadas a las islas (2010: 175).

No obstante en los argumentos de los movilizados el achique del Teatro de Operaciones del Atlántico Sur se realizó sólo con fines económicos, para que numerosos veteranos no fueran reconocidos como partícipes de la guerra. En ese sentido el conflicto también es en el plano del derecho. Este ardid esgrimido por diferentes estudios jurídicos que acompañan las demandas de movilizados sustenta el pedido de relectura jurisdiccional de los Teatros de Operaciones. Pese a ello, 
el Ministerio de Defensa ratificó en 2012 el área de cobertura del TOAS 11 .

Los casos abordados: movilizados en Chaco y Corrientes.

La dimensión identitaria del problema.

Como dijimos al inicio, trabajaremos dos casos a nivel subnacional, en las provincias argentinas de Chaco y Corrientes, acontecidos específicamente en sus ciudades capitales. En este apartado nos abocaremos a los fundamentos de los movimientos de movilizados desde los cuales reclaman su legitimidad en tanto veteranos de guerra. Delimitaremos las asociaciones intervinientes en el proceso y algunos hechos previos a las presentaciones de proyectos de ley en las legislaturas de cada provincia. Cabe destacar una primera diferencia entre ambos: mientras que en Corrientes la presentación del proyecto y las acciones en el espacio público fueron llevados a cabo ex soldados nucleados en un solo movimiento, en Chaco intervinieron varias asociaciones que incluso tuvieron disputas entre sí.

\section{Corrientes}

En 2005 la Asociación “Veteranos del Teatro de Operaciones del Atlántico Sur Clase 1962” de la provincia de Corrientes (en adelante TOAS C/62) $\frac{12}{1}$ inició una serie de acciones concretas consistentes en el envío de solicitadas a distintos medios dando a conocer la problemática y, posteriormente, tres cortes del puente interprovincial "Manuel Belgrano" que une las ciudades de Resistencia y Corrientes. En las solicitadas y las declaraciones públicas, los voceros de la Asociación establecieron el "piso legal” desde el cual realizaban su reclamo.

Una solicitada del 28 de abril de 2005 manifestaba:

Nuestra lucha pretende el reconocimiento de los legítimos derechos que nos asisten por el hecho de habernos encontrado a un paso de volar hacia las Islas (...). Queremos dejar bien claro que no pretendemos arrebatar los logros obtenidos por otros con toda justicia. Tan solo aspiramos a que la sociedad toda y en particular los funcionarios y autoridades con poder decisorio tomen conciencia de que excluir de los beneficios otorgados a una parte de los convocados al frente de batalla, con el único argumento de no haber disparado sus fusiles o no haber experimentado en carne propia la metralla del enemigo, representa un acto de absoluta injusticia e ingratitud que merece una condigna reparación $\underline{13}$.

Como se puede apreciar, la fuerza del argumento se liga a, por un lado, la definición militar de los Teatros de Operaciones que anteceden al decreto 509/88; y por otro a la Convención de Ginebra que sitúa, para los miembros de la Asociación, a la guerra de Malvinas bajo los mismos términos que 
cualquier conflicto bélico internacional. Estar ungidos del uniforme, ocupar un lugar logístico dentro del TOAS, portar un arma y esperar el cruce a Malvinas, son motivos suficientes para ser reconocidos como veteranos.

A fines de 2005 los TOAS C/62 realizaron tres cortes de puente como medida de protesta y presión para abrir la posibilidad de reunirse con funcionarios del Estado provincial y nacional. En uno de estos cortes mantenían los primeros argumentos mencionados:

Nosotros, si bien no entramos en combate, participamos de la guerra desde el continente. Trabajábamos apoyando a nuestros compañeros, proveyéndolos del material necesario para poder pelear, pero nunca fuimos reconocidos como veteranos de guerra (...). La Convención de Ginebra nos reconoce como veteranos de Guerra, pero las leyes argentinas no $\underline{14}$.

Chaco

En Resistencia la primera manifestación pública de los movilizados fue el 5 de diciembre de 2006 cuando un miembro de la Asociación de Veteranos de Guerra TOAS se subió a la antena de un Hipermercado de la ciudad en reclamo de proyectos productivos para el sector. En esa ocasión, el referente del movimiento, José Luis Acuña, manifestó que "la demanda es ser reconocidos como veteranos de guerra” $\underline{15}$. Días después, los miembros del movimiento lograron una audiencia con la Ministra de Defensa, Nilda Garré, donde manifestaron a la prensa:

Nosotros somos el orejón del tarro de esta sociedad, porque a nosotros (sic) nos han convocado para una guerra, a una guerra fuimos... y hoy por hoy, tenemos el desprecio total de las Fuerzas Armadas, del Gobierno, y encima tenemos que soportar el desprecio de lo insensibles y egoístas que son los compañeros nuestros que estuvieron en Malvinas"트.

A principios de 2007, se establecieron una serie de reuniones en la sede del partido radical de Resistencia y a finales de ese año se llevó a cabo el primer corte del puente interprovincial por parte de movilizados chaqueños. El corte, al igual que en el caso correntino, estuvo ligado al tratamiento en la Cámara de Senadores de la Nación de uno de los proyectos presentados, por lo cual la acción no estaba ligada aún al ámbito local. En tal sentido, Daniel Barrientos, del Centro de Movilizados y Convocados de Malvinas Chaco ${ }^{17}$ (C.M.C.M.CH) explicitó que

según el Pacto de Ginebra, a los movilizados para un conflicto bélico les corresponden los mismos beneficios a que los que llegan al combate (...), muchos fueron afectados emocionalmente sólo por el hecho de saber que iban a una guerra. Como ex soldados conscriptos movilizados no buscamos la igualdad absoluta con aquellos ex combatientes que estuvieron en 'efectivas acciones de combate'. Por tal sentido, un proyecto en el Congreso propone una pensión de guerra equivalente al 70\% de los beneficios previstos en la Ley $23.848^{\underline{18}}$. 
El 29 de enero de 2008 el flamante gobernador Jorge Capitanich (PJ) decreta la creación de un registro de movilizados y convocados, lo cual había prometido un mes antes al sector. El Decreto 355/08 establecía la necesidad de un relevamiento que quedó bajo fiscalización de una serie de asociaciones de ex soldados: la Asociación "Región Noroeste Argentino de Convocados y Movilizados por Malvinas”; la Asociación “Soldados bajo bandera- conflicto Malvinas Argentinas”; la Asociación “Centro de Movilizados por Malvinas Sudoeste Chaqueño” y su homóloga de El Impenetrable, y el Centro de Movilizados y Convocados de Malvinas Chaco $\underline{19}$. Como podemos apreciar, los movimientos adscriben a diferentes nominaciones en el amplio abanico posible y se hacen visibles a partir del llamado del Ejecutivo. A su vez, el 1 de abril de ese año, la gobernación provincial decreta "el reconocimiento Histórico y Moral para los convocados, movilizados que formaron parte de la gesta de Malvinas en el año 1982” (sic) ${ }^{\underline{20}}$, lo cual marca las condiciones de lo que vendrá. El Decreto 1155/08 formó parte de las promesas hechas por Capitanich a fines de 2007 y se instituyó en un elemento de referencia para fortalecer el pedido de beneficios económicos.

La dimensión estratégica-legal

En este apartado nos interesa dar cuenta de los proyectos de ley presentados en ambas provincias, y las formas en que los expedientes y la legislatura se convierten en campos de batalla. Es decir que nos detendremos en el análisis de los proyectos, los expedientes y los tratamientos legislativos, sin tomar en cuentas las acciones llevadas a cabo en el espacio público por los movimientos implicados.

\section{Corrientes}

En el caso de Corrientes, el TOAS C/62 logró materializar sus reclamos en un proyecto de ley provincial presentado por los diputados Pedro Braillard Poccard (PANU $\underline{21}$ ) y Marcos Costa (PANU), bajo Expediente 3544/06, en el que se amplían las bases argumentales, con el objetivo de establecer un régimen previsional para los veteranos del TOAS. El proyecto, que ingresó a la Legislatura el 20 de septiembre de 2006, establecía en su Artículo 1 que

[e]l estado de la provincia de Corrientes reconocerá la condición de Veterano de Guerra del Operativo Malvinas a todos aquellos oriundos de nuestra provincia, que hayan participado del conflicto dentro del Teatro de Operaciones, ya sea como fuerzas de ataque en la propia isla o de apoyo logístico, incluyendo la Base Aérea y su zona de influencia, emitiendo a tal fin un Certificado de Veterano de Guerra $\underline{22}$.

A su vez estipulaba un beneficio previsional especial correspondiente al $80 \%$ de lo erogado a los excombatientes bajo la Ley 5507/03. A pesar de una serie de indefiniciones, el texto daba cuenta de una batería legal de respaldo al reclamo movilizado. Por ejemplo el Pacto de San José de Costa Rica (en cuanto a los deberes del Estado para los ciudadanos que hayan prestados servicios especiales) o 
una resolución de la Jefatura de Gabinete de Ministros (Res. 04/2001) que establece que

a los fines de la percepción del beneficio previsto por el Decreto $\mathrm{N}^{\circ} 1244 / 98 \underline{23}$ se aclara que los términos: Ex Combatientes, Veteranos de Guerra o Veteranos de Malvinas son sinónimos entendiéndose por tales a todo aquel personal de oficiales, suboficiales y soldados de las fuerzas Armadas y de Seguridad que hayan participado en las acciones bélicas llevadas a cabo en las jurisdicciones del TOM y del TOAS, y civiles que se encontraban cumpliendo funciones de servicios y/o apoyo en donde se desarrollaron las acciones $\underline{24}$.

Como mostramos, el proyecto presenta la necesidad de reconocer a los movilizados como veteranos de guerra y así plantear la eximición de impuestos, entrar al régimen previsional, lograr la reducción de tarifas energéticas, entrar en el plan de viviendas, y por supuesto percibir la pensión. El Proyecto cae tras la interpretación del Instituto de Previsión Social de Corrientes, que en su informe adjunto al expediente afirma que ya hay dos beneficios: para excombatientes, y por discapacidad. No obstante, el 7 de junio de 2007, el diputado Jorge Abib (PJ) presentó un nuevo proyecto bajo expediente 3777/07, cuyo objeto fue otorgar - según manifiesta el artículo 1- una "pensión a exsoldados a disposición de las Fuerzas Armadas durante el Conflicto Bélico de Malvinas, de carácter mensual y vitalicio”르.

De esta forma la condición de veterano excedía incluso la cobertura del TOAS (más allá del problema de la definición de sus límites) y englobaba a todo soldado correntino bajo bandera en cualquier punto del país durante los más de tres meses de guerra. Lo "veterano" se oculta como nombre $\frac{26}{}$ (atendiendo de esta forma al reclamo del excombatiente de dividir las experiencias en la ley, como veremos). El documento tuvo media sanción en $2007 \underline{27}$ pero recién se trató su aprobación el 28 mayo de 2008.En el momento del tratamiento del proyecto se desató un conflicto del que daremos cuenta a través del relato de un diario correntino:

Antes de iniciarse la sesión ambos sectores (ex combatientes y movilizados) se habían congregado afuera de la Legislatura. Los primeros para rechazar el proyecto los segundos para apoyarlo. El grupo de ex combatientes ingresó al recinto y copó las gradas superiores, cuando ingresaron los legisladores comenzaron a entonar el Himno Nacional, haciendo que los diputados se paren a cantarlo. Luego entonaron el cántico "Malvinas, Malvinas, la lucha no termina”. Finalizada la sesión la presidente de la Comisión de Hacienda y Presupuesto, Marina Anderson dijo: "Hay que debatir el proyecto, pedir a la Nación el padrón de los movilizados y otorgarles la pensión. Lo más importante es que el debate se produzca y que cada uno fije su postura" sostuvo la legisladora, que además reprochó la actitud de algunos de sus pares que "sin fundamento" pidieron que vuelva a Comisión. El proyecto tendría un destino impreciso. Algunos diputados sostienen que no corresponde la pensión, las apreciaciones son más subjetivas que objetivas. En tanto otras de las advertencias que se hace apuntan a los fondos para pagar este beneficio y a la confección del padrón. La discusión se dio en la labor parlamentaria, allí varios legisladores hicieron objeciones de tipo ideológico. En esta reunión varios diputados adelantaron su voto negativo. A este se debe sumar la inevitable presión de los ex combatientes que demostraron su poder de movilización y su desagrado con el proyecto. $\underline{28}$ 
Finalmente el proyecto no se trató y fue enviado a Comisión de Asuntos Constitucionales. Luego de la vuelta a Comisión, el Expediente 3777/07 se transformó en una zona de disputas. El 5 de junio de

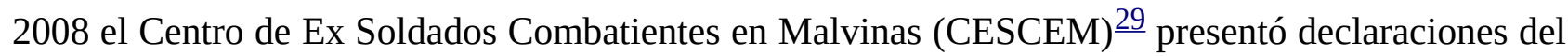
Ministro Randazzo donde se prohíbe a un grupo de movilizados la entrada al acto oficial del 2 de abril de ese año. El 13 de junio el diputado Aquino Britos $\underline{30}$ (UCR) presentó dos argumentos de oposición al proyecto: no son excombatientes y el gasto de cobertura es muy alto para que la provincia pueda afrontarlo. El 30 de junio Aquino Britos hizo el pedido oficial para que el proyecto pase a la Comisión de Asuntos Constitucionales y Legislación que él presidía. En tanto que el 1 de agosto el TOAS C/62 inició una serie de notas para intentar "mover” el expediente. Primero presentando el apoyo de la Federación de Veteranos de Guerra de la Provincia de Corrientes $\underline{31}$. Luego, adjuntaron escritos donde se pone en duda las versiones oficiales y se inscribe al continente en la guerra a partir de la entrada de ingleses y la Operación Mikado. Pese a estos intentos por lograr el nuevo tratamiento el expediente no se movió hasta su archivo en $2009 \underline{32}$.

Sin embargo, el 12 de mayo de 2009 ingresó a la Legislatura provincial un proyecto de declaración presentado bajo expediente 4776/09 por los diputados Héctor Snihur (PJ), Marina Anderson (PJ) y Aurelio Díaz (PJ). El documento establecía la necesidad de un reconocimiento histórico y moral para todos los ex soldados "conscriptos bajo Bandera, convocados y/o movilizados que de una u otra forma participaron en el conflicto argentino - británico por la recuperación de las Islas Malvinas, y en defensa de nuestra Soberanía Argentina, entre el 2 de Abril y el 14 de Junio de 1982 ”33.

Aunque se corrió del problema de los beneficios económicos, hay en su letra un intento de dar cuenta del conflicto implicado en los proyectos anteriores (sumado a un contexto nacional de presentación de proyectos similares). En sus fundamentos, el texto aduce que

[c]on el deber de proteger el territorio Nacional, estos conscriptos bajo Bandera, convocados y movilizados, han servido a la Patria desde los distintos cuarteles y defensas de fronteras, preparándose para concurrir al lugar de combate. La sociedad no tiene incorporado en el sentimiento colectivo un reconocimiento a los soldados movilizados que no viajaron a las Islas (...). Considerando que toda la costa continental argentina era un frente de batalla ante la amenaza constante de los ingleses de bombardear ciudades del continente, era necesario que también soldados pertrechados estuvieran en esta zona de guerra $\underline{34}$.

Este proyecto obtuvo media sanción pero su aprobación definitiva se trató en abril de 2010. Antes, el 29 de marzo de 2010 el flamante mandatario provincial Ricardo Colombi $\frac{35}{3}$ promulgó el Decreto $1350 / 10$ que

Instituye el reconocimiento histórico y moral para los convocados, movilizados y todas aquellas personas que de una u otra forma intervinieron en la gesta de Malvinas [aduciendo que] resulta necesario para el pueblo y gobierno de la provincia de Corrientes, reconocer a los que combatieron, a los que se movilizaron y a quienes participaron en la Gesta de Malvinas, defendiendo la soberanía nacional en este territorio $\underline{\underline{36}}$. 
Como veremos, este decreto tuvo un efecto concreto respecto a las acciones del movimiento en el espacio público, pero también abonó la esperanza de lograr -al menos- el reconocimiento del poder legislativo. En el expediente 4776/09el TOAS C/62 volvió a adjuntar documentación probatoria de su calidad de veterano, y elevó una nota donde afirman no entender

porqué cuesta tanto otorgarnos los derechos que por historia nos corresponden, al mismo tiempo informarles de varias documentación que el propio Gobierno de la Provincia los avala, y también necesitamos una respuesta, que hasta ahora no comprendemos si a la defenza de nuestra soberanía argentina y no a nuestros derechos $(\text { sic) })^{\frac{37}{}}$.

El proyecto obtuvo media sanción y tratamiento favorable sin modificaciones en las comisiones, y se trató su aprobación definitiva el 22 de abril de 2010. Sin embargo, la sesión terminó con la vuelta a comisión del proyecto, casi sin tratamiento. El proyecto de declaración se archivó el 9 de marzo de 2011.

Chaco

En la provincia del Chaco, el 15 de abril de 2008, ingresó a la bicameral el proyecto de ley N780/08 presentado por los diputados Eduardo Siri, Elba Altamiranda, José de Bórtoli y María Dolores Cristofani (todos de la UCR) ${ }^{38}$ elaborado en conjunto con el Centro de Movilizados y Convocados de Malvinas Chaco (C.M.C.M.CH.).El proyecto original instituía, en su artículo 1, “un Reconocimiento Histórico Moral, a los ex soldados conscriptos chaqueños de las Fuerzas Armadas que hubieran sido convocados movilizados, y movilizados en el período que comprende el 2 de abril y el 14 de junio de 1982, donde el destino sería en su caso, el litoral marítimo patagónico (T.O.A.S.), al sur del Paralelo $42^{\circ}$ ”. A su vez, establecía una pensión “equivalente al setenta por ciento (70\%), de la pensión provincial del Veterano de Guerra establecida en la Ley 4569/99 y sus modificatorias” $\underline{39}$.En los fundamentos se hace referencia al Decreto 1155/08 que constituyó un reconocimiento moral e histórico por parte del ejecutivo chaqueño. En los medios locales se convocó a una reunión encabezada por la Comisión de Legislación del Trabajo de la Cámara de Diputados estipulada para el 6 de mayo de ese año, a la cual se invitó a "todas las asociaciones de Soldados Convocados y Movilizados de la provincia del Chaco por el conflicto bélico por las Islas Malvinas" $\underline{40}$. Al igual que en el caso correntino, el proyecto encontró un rápido rechazo de los excombatientes expresado en la nota del 5 de mayo adjunta al expediente, donde el CESCEM Chaco define como "estafa moral” al Proyecto 780/08. "Se quiere FABRICAR o CLONAR (sic) Veteranos de Guerra, cuando en realidad lo que se persigue es un fin económico solamente (...) esta Provincia los quiere colgar de nuestras leyes”쓰.

En julio la Comisión de Legislación del Trabajo presentó una modificatoria del proyecto original estableciendo el carácter de pensión graciable y estableciendo su monto en un 70\% categoría 7 Personal de Servicio -Grupo 1 del Escalafón para el personal del Poder Ejecutivo, quitando de esta forma la referencia a la ley de pensión para excombatientes. Pero más importante es la visibilidad 
del despacho dividido entre los bloques opositores, la UCR y el PJ más sus aliados. El proyecto no logró ser tratado y quedó en Comisión. Ante esto, el C.M.C.M.CH adjuntó una serie de notas para forzar el tratamiento. En principio envió una nómina de posibles beneficiarios, y en septiembre de 2008 presentaron un petitorio con lo resuelto en asamblea: iniciar una serie de movilizaciones para pedir por la aprobación del proyecto. A su vez, se adjunta una serie de notas dirigidas al gobernador Capitanich y en noviembre se suman 250 folios con 6115 firmas en apoyo al proyecto. Pese a ello, el tratamiento no se movería hasta abril de 2009 cuando la Comisión de Legislación solicitó al entonces Ministro de Gobierno, Domingo Peppo, los resultados del censo del año anterior destinado al sector en pugna.

El 27 de mayo de ese año el bloque de la UCR impuso su mayoría y sancionó la Ley 6.347 pese a la negativa justicialista $\frac{42}{}$. Entre los argumentos no sólo se esgrimieron razones heroicas en la gesta, también se recordó los Decretos 355/08 (registro Malvinas) y 1155/08 (de reconocimiento histórico y moral) de Capitanich que dieron un marco de reconocimiento al sector. La bancada oficialista intentó mantener el proyecto en Comisión pero la mayoría radical y los abucheos de los movilizados presentes lograron la aprobación definitiva. No obstante, la ley fue vetada parcialmente semanas después por el Ejecutivo provincial, aduciendo razones presupuestarias y modificando los artículos 1 y 2, bajando el monto del $70 \%$ al 50\% de la Categoría 7 y estableciendo incompatibilidad con otros beneficios similares y especificando que la pensión será otorgada a chaqueños convocados por el Distrito Militar Chaco. En una nota adjunta al expediente, el C.M.C.M.CH manifestó la aceptación del veto, siempre que se establezca el paralelo $42^{\circ}$ como referencia, es decir que no todos los ciudadanos bajo bandera estarían al amparo de la ley sino únicamente aquellos movilizados a las bases del sur. Sin embargo, en agosto el mismo Centro envía una nota pidiendo que se apruebe el proyecto original sosteniendo la compatibilidad con otros beneficios y el 70\% de la Categoría 7. Esa nota fue acompañada de otras dos emitidas por la Mesa Provincial de Trabajo por los Movilizados, Convocados y Bajo Bandera donde participaban movimientos de Resistencia, y una nota de la asociación del Sudoeste chaqueño que adhirió al pedido de la Mesa. Sin embargo, ambas solicitaron que no se discrimine con la referencia al paralelo ya que eso dejaría a un numeroso conjunto de beneficiarios fuera de la cobertura. El expediente se convirtió en un espacio de disputa entre los mismos movilizados. En octubre de 2009, la cámara aceptó por Resolución 2512/09 el veto parcial del gobernador y el 26 de noviembre la Presidenta de la Cámara de Diputados, Alicia Mastandrea (UCR), exigió al Ejecutivo que publique en el Boletín Oficial la Ley 6.347플.

Empero, el decreto de reglamentación tardó casi un año en emitirse. El 06 de septiembre de 2010 el gobernador estableció el Decreto 1648/10 donde reglamentaba la ley: 50\% de la categoría 7, sólo para movilizados al sur del paralelo $42^{\circ}$ e incompatibilidad con otros beneficios previsionales otorgadas por Nación. Pese a estar presentes en el anuncio oficial los referentes de la Asociación Soldados Bajo Bandera- conflicto Malvinas Argentinas(Juan Carlos Medina), el de la Asociación Regional Noreste Argentino de Convocados y Movilizados de Malvinas(Oscar Insaurralde), y el del Centro de Movilizados y convocados Malvinas Chaco (Daniel Barrientos), la aprobación de esta ley no fue el final del derrotero legal respecto al tema. Pero en principio las modificaciones posteriores no tuvieron la necesidad de presentar nuevos proyectos de ley por parte de los movimientos implicados, sino presionar para ser reconocidos en los marcos ya establecidos. 
Luego de algunas denuncias por discriminación en los marcos de la ley, en 2011 surgieron dos leyes que modificaron artículos de la 6347 para incluir a los llamados acuartelados (que cumplieron funciones al norte del paralelo $42^{\circ}$ ), y dos leyes más en 2012. Para hacer una síntesis, en junio se aprobó la Ley 6816 que modificaba el artículo 1 de la antedicha para sumar a acuartelados y bajo bandera. La misma fue vetada completamente por razones presupuestarias. En agosto se sancionó la Ley 6848 que redujo el porcentaje de la pensión a un 30\% de la Categoría 7 pero que incluyó a todos los movilizados, convocados, acuartelados y bajo bandera. Ya en 2012 se sancionaron dos leyes distintas, la 6990 que volvió a modificar el artículo 1 y 2 de la 6347 para reponer el paralelo como referencia y el 50\% como monto; y la Ley 6991 que establece una pensión al 30\% para

ex soldados chaqueños, convocados por el Distrito Militar Chaco, que hubieran sido acuartelados o convocados y que no hayan sido movilizados a la zona de despliegue continental al Sur del Paralelo $42^{\circ}$ o tomado parte de las operaciones militares en el archipiélago, durante el período comprendido entre el 2 de abril y el 14 de junio de 1982, en carácter de reconocimiento histórico moral y que estuvieren comprendidos en el decreto 355/08는

De esta forma, la legislación chaqueña reconoce tres beneficiarios partícipes de la guerra de Malvinas: excombatientes o veteranos; movilizados y acuartelados.

La dimensión estratégica-política.

\section{Corrientes}

El proyecto presentado bajo Expediente 3544/06 en la legislatura correntina implicó un punto de inflexión no sólo por ser el primer instrumento legal provincial que atendía el problema de los movilizados , sino porque además marcó el inicio de una acción concreta: el 21 de septiembre, un día después de la presentación del documento en la Legislatura correntina, la Asociación "Veteranos del Teatro de Operaciones del Atlántico Sur Clase 1962” montó una carpa en la plaza 25 de mayo de la capital correntina con el objetivo de presionar la aprobación del proyecto. Desde otro lugar, en conferencia de prensa, el Centro de Ex Soldados Combatientes de Malvinas de Corrientes (CESCEM) manifestó públicamente su rechazo a la medida de los TOAS C/62, pero sobre todo al proyecto ingresado. El acampe se sostuvo por más de 42 meses, finalizando el 30 de marzo de 2010 tras la promulgación del Decreto Provincial 1350/10. Como vimos, el proyecto establecía el pedido de reconocimiento histórico y beneficios en el plano económico. Días posteriores al 21 de septiembre, el CESCEM se manifestó públicamente en contra del proyecto presentado y de la protesta, argumentando que

[p]retender igualar las situaciones que vivimos los que estuvimos en combate con aquellos que estuvieron en el Teatro de Operaciones Sur (TOS) es totalmente descabellada (...) creemos que cada situación debe ser abarcada con leyes específicas que contengan las diversas realidades vividas, pero que no sean comprendidas en una 
injusta ley global $\underline{45}$.

Hasta este punto los excombatientes rechazaban ser englobados en los mismos parámetros, marcando la distancia desde la experiencia bélica. Como vimos, hay dos aspectos encontrados que condensaron los reclamos de un lado y del otro. Por parte de los movilizados, la búsqueda de reconocimiento estuvo ligada a igualar la guerra de Malvinas con todas las guerras del mundo bajo la Convención de Ginebra, por ende quienes estaban en las bases continentales entre el 2 de abril y el 14 de junio de 1982 deben ser considerados veteranos de guerra; en cambio, los excombatientes marcaron la diferencia tomando en cuenta no sólo las particularidades de esta guerra $\frac{46}{}$, sino, y sobre todo, la lucha que ellos encarnaron para conseguir su propio reconocimiento en la posguerra. Al no ser "lo mismo" no deberían formar parte de los mismos parámetros frente al Estado.

Hubo mucha gente que murió a nuestro lado y nosotros pasamos días sin comer. Llevamos 24 años luchando por nuestros derechos y por el de nuestros camaradas caídos en las islas. Nos parece una falta de respeto que ahora (...) uno que fue chofer de un camión en la Patagonia, es lo mismo que uno que estuvo herido y sin comer durante cuatro días en la isla. No estamos en contra de ellos, pero sí queremos que los legisladores hagan notar la diferencia entre unos y otros, porque sin discriminación, en este caso, no todos tuvimos las mismas responsabilidades y queremos que eso quede en claro en la ley $\stackrel{47}{ }$.

El pedido excombatiente apuntaba a los diputados y senadores, y estuvo ligado a las características de la letra legal que los nombraba. Tanto en la legislación nacional como en la provincial el término utilizado es el de "ex soldados combatiente" bajo el parámetro de reconocimiento en la acción bélica. Sin embargo, las distintas modificaciones que sufrió la Ley Nacional 23.848/90 (Mod. Ley 24.343/94, 24.652/96, 24.892/97) para otorgar la pensión vitalicia a oficiales y suboficiales, pero sobre todo los Decretos Nacionales 1.357/04 y 886/05 que hacen alusión a la pensión en términos de "Veteranos de la Guerra del Atlántico Sur", desarticula el nombre excombatiente.

En este hiato ingresó el pedido de los TOAS C/62:

Seguimos acá porque tenemos esperanzas de sacar nuestro proyecto de ley provincial. Ellos (los excombatientes) se ofenden, dicen, creen y están haciendo creer que si sale nuestra ley les va a perjudicar a ellos, y eso no es así, porque si sale nuestra legislación será independiente de la que tienen (...). Yo tengo muchos artículos militares que dicen que el movilizado es veterano de guerra. En Estados Unidos, de los que fueron a Vietnam de cada 5 personas, 4 estuvieron en la retaguardia y 1 en el frente. Nosotros no decimos que estuvimos en la retaguardia, consideramos que estuvimos en el TOAS cumpliendo una función estratégica militar. Sin nosotros en ese lugar, ellos no hubieran estado $\underline{48}$.

Respecto a la presentación del segundo proyecto que los diferenciaba (Exp. 3777/07) los miembros del acampe manifestaron no querer "ninguna ley de enganche con los ex combatientes ni veteranos de guerra, la idea es no dañar ni entrometernos con sus beneficios y conquistas, creemos que nuestro reclamo también es justo" $\underline{49}$.Sin embargo, la presentación de este nuevo proyecto fue 
rechazada por el CESCEM aduciendo que en sí apuntaba a la modificación de la Ley provincial $5507 / 03$.

A nivel provincial, la coordinadora de Combatientes en Malvinas también rechazó el proyecto por “confuso” en cuanto a sus alcances. El 28 de mayo de 2008 fue la fecha de tratamiento del proyecto con media sanción presentado por Abib. Días antes, el CESCEM y la Coordinadora Provincial de Combatientes de Malvinas habían manifestado públicamente que algunos de sus miembros asistirían a la sesión para intentar frenar el tratamiento. Por el lado de los TOAS C/62 la frontera con los excombatientes se puso en términos de destino: “[e]l hecho de que a él (José Galván, presidente del CESCEM) le tocara ir al frente de batalla fue una cuestión de estrategia militar o una cosa del destino. Si el conflicto continuaba yo pasaba al frente de batalla” $\underline{50}$. En otros términos el presidente del Centro de Excombatientes de la ciudad de Bella Vista, Carlos Zini, remarcó que es un “atropello moral contra los ex combatientes dándole el título de veteranos de guerra cuando en ninguna ocasión pisaron el terreno de combate”⒈ Como ya mencionamos, en el momento del tratamiento del proyecto se desató el conflicto que derivó en la vuelta a Comisión y posterior archivo.

La falta de movimiento de expedientes y el desgaste por el tiempo de acampe motivaron que a través de un decreto (el 1350/10)de reconocimiento histórico y moral los movilizados abandonen la plaza, el 30 de marzo de 2010 tras 42 meses. Más allá de no haber alcanzado el objetivo planteado en 2006 respecto al proyecto de pensión, en las primeras declaraciones públicas del TOAS C/62 hay una clara variación en palabras de dos referentes del acampe:

Tenemos sentido del tiempo, el modo y el espacio. Los ex combatientes están en un pedestal, han dado lo máximo en beneficio del país. Nosotros desde nuestro lugar cuidábamos los aviones, la mejor arma del país en ese momento y consideramos que nuestro aporte ha sido realmente importante para la batalla aérea $\underline{52}$.

(...) desde el continente salían los aviones para atacar a la flota inglesa y fueron los que más daños causaron a los ingleses (...) tuvimos 17 muertos, hubo comandos ingleses y tuvimos enfermos no sólo física sino también psicológicamente. Es decir que padecimos y sufrimos las mismas consecuencias que los que estaban en primera línea. En una guerra no sólo el que combate es veterano de guerra, también es la de tropas que se movilizan y hacen una ayuda psicológica o a nivel de pertrechos (manipuladores de misiles, fusiles, cargar aviones) $\underline{53}$.

Para nosotros éste es un reconocimiento moral histórico, no es una pensión o una ayuda social, es nuestra identidad $\underline{54}$.

Como vemos, si en un primer momento marcaban su reclamo en el plano legal, más de tres años después del acampe parecen tener suficiente homogeneidad para poner el plano de la experiencia bélica como un aspecto histórico susceptible a hacer público. Por su parte, desde el CESCEM mantuvieron los argumentos esgrimidos desde el primer momento para rechazar el decreto:

Le dieron demasiada prensa a esta gente que no es combatiente. Esto es lamentable, tenemos que de una vez por todas decir las cosas por su nombre. Nosotros somos los verdaderos ex soldados, los otros movilizados no (...). Nosotros defendemos la 
memoria de los compañeros caídos en Malvinas que son los verdaderos ex combatientes $\underline{55}$.

Ya sin el marco del acampe, se trató el proyecto de declaración bajo Expediente 4776/09 el 22 de abril de 2010 que terminó, como vimos, con una vuelta a Comisión. Posterior a la sesión, como podemos ver en esta crónica periodística, es agredido el legislador Armando Aquino Britos:

No bien comenzó la jornada, dos grupos bien diferenciados comenzaron a presionar: los ex combatientes, para que no se trate, y los movilizados, recientemente reconocidos en un decreto, para que saliera la resolución. Los legisladores buscaron una salida elegante: la vuelta a comisión. Pero a los que estaban a favor de la resolución no les agradó nada. El blanco de las agresiones fue el diputado del bloque Alem, ex combatiente de Malvinas, Armando Aquino Britos, que, sin muchas argumentaciones, alegó que no se tratara la declaración de reconocimiento histórico y moral para todos los ex soldados conscriptos que de una u otra forma participaron en el conflicto argentino. Apenas se retiraron de la Legislatura anunciaron que irían por Aquino Britos. Y así fue. Cuando se retiró, el legislador fue agredido primero verbalmente. Una custodia fuerte de la Policía, con infantería y el $\mathrm{PAR}^{\underline{56}}$, buscó evitar lo inevitable: el uso de la violencia para manifestar el desacuerdo por lo resuelto en Diputados $\underline{57}$.

Chaco

El Proyecto 780/08 presentado el 15 de abril de 2008 en la legislatura del Chaco también dio pie a una serie -distinta- de movilizaciones y acciones en el espacio público. Antes de dar cuenta de algunas de ellas cabe señalar una cuestión importante: a diferencia de Corrientes, donde el CESCEM tiene una unidad y peso muy fuerte en la provincia, las asociaciones de excombatientes y veteranos chaqueñas tienen una mayor dispersión y tensión entre sí. El Centro de Ex Soldados Combatientes en Malvinas Chaco, si bien importante en los inicios de la posguerra, fue perdiendo peso, mientras que la Asociación de Veteranos “2 de abril” tiene numerosos pedidos de intervención por parte de algunos afiliados y ex afiliados $\underline{58}$. Por ende, ninguna de las dos tiene el capital acumulado que sí ostentan sus camaradas correntinos.

El 6 de mayo de 2008, fecha de la convocatoria del Poder Legislativo a las asociaciones de movilizados y convocados, un grupo de excombatientes chaqueños apoyados por los "Ex Soldados Combatientes en Malvinas" de la ciudad de Bella Vista, Corrientes, marcharon a la Legislatura en repudio al proyecto de ley $\underline{59}$. Dos meses después, el 16 de julio, durante la sesión que tenía estipulado el tratamiento del documento, se enfrentaron a golpes miembros del CESCEM de Corrientes y el Centro del Bella vista con un grupo de movilizados pertenecientes al C.M.C.M.CH y otras asociaciones. José Galván, presidente del movimiento correntino y referente de la coordinadora de centros de esa provincia, afirmó que "hemos ido a acompañar a los ex soldados combatientes en Malvinas del Chaco para que no se plasme en realidad la Ley de reconocimiento a los Convocados y/o Movilizados de aquella ciudad, Movilitruchos”0. Un día antes, habían presentado una solicitada a los medios locales donde afirmaban que 
Malvinas por fotos o por la televisión, con aquellos que dejaron todo por su patria en el campo de batalla. Hacemos propicia la oportunidad para informar que el CESCEM, se encuentra analizando la posibilidad de presentar un recurso de amparo colectivo, a fin de cesar estas prácticas políticas que se vienen promocionando por medio de la sangre derramada de nuestros héroes ex combatientes $\underline{61}$.

Asimismo, el Consejo Provincial de Veteranos de Guerra del Chaco envió, el 29 de julio, una solicitada donde se expresaba en términos similares:

Es seguro que muchos que colaboraron tienen necesidades y demandas, pero no se cuelguen de la gesta de Malvinas, diciendo yo colaboré. Señores: Sabemos (sic) nosotros, sabe el pueblo y la historia que en el continente no hubo guerra, que la guerra fue en las Islas Malvinas, por lo tanto, no confundan más y obren a conciencia y con grandeza. Son ustedes los responsables o no de desvirtuar las leyes, debilitar a instituciones democráticas o legislar para la Nación, y no por la necesidad del voto $\underline{62}$.

A partir de septiembre de 2008 empezaron una serie de medidas que involucraron al sector de movilizados, por el no tratamiento del proyecto. El día 3, el Centro de Movilizados y Convocados de Malvinas Chaco llevó a cabo una asamblea donde decidieron interrumpir el ingreso a la ruta que comunica la ciudad de Resistencia con la de Isla del Cerrito, y luego, el 14 de marzo llevaron adelante un acampe en la Plaza 25 de Mayo de 1810 de la capital chaqueña. El acampe duró cinco días y su fin tuvo que ver con la firma de un acta donde se estableció que

los movilizados 'manifiestan su voluntad de entablar una mesa de diálogo con el Gobierno del Chaco, a fin de dar tratamiento a las demandas de la agrupación’. Detalla además que se procede al 'cese del acampe montado en la plaza 25 de mayo de 1810 ante la predisposición mostrada por las autoridades provinciales en el sentido propuesto'. El documento lleva la firma de Daniel Barrientos y Roberto Báez del C.M.C.M.C.H. y Américo Ocampo, coordinador Legal y Técnico del Ministerio de Gobierno, Justicia y Trabajo de la provincia $\underline{63}$.

Estas acciones fueron rechazadas por otros involucrados en el conflicto, particularmente la Asociación Regional Noreste Argentino de Convocados y Movilizados de Malvinas. Uno de sus referentes, Oscar Insaurralde, manifestó que

este reducido grupo de gente no movió un dedo en los últimos 12 años por una ley que nos ampare o cobije y hoy piden a diputados de la Alianza, los que nunca nos atendieron que sancionen una ley a favor de excombatientes; por estos motivos un grupo numeroso de personas que teníamos otra postura nos alejamos hace tiempo de ellos y hoy día estamos trabajando en forma coordinada con el ejecutivo provincial $\underline{64}$.

La disputa que pudimos ver entre bloques dentro de la Legislatura también se hizo visible entre los movimientos implicados. Como ya mencionamos en el apartado anterior, el C.M.C.M.CH generó una serie de acciones en la vía pública (puestos en la peatonal resistenciana y frente a la Municipalidad de la ciudad) para conseguir las 6.115 firmas presentadas y adjuntadas al proyecto entre octubre y noviembre de 2008. 
Al año siguiente, el 1 de abril de 2009, miembros de la Asociación Regional se encadenaron a la Casa de Gobierno provincial ya que “[el gobernador Jorge Capitanich] el año pasado nos solicitó un impass de espera hasta el 31 de marzo. Le hemos dado ese plazo y como ayer se cumplió, hoy empezamos con medidas de fuerza que vamos a llevar adelante en toda la provincia” $\underline{65}$. Esta iniciativa se desactivó a partir de la activa relación entre la Asociación Regional y miembros del gobierno, de la cual no participaron la C.M.C.M.CH y la Asociación Soldados Bajo Bandera. Esta última, ante el veto parcial de la Ley 6347 decidió, el 8 de junio, llevar adelante un acampe en la misma Plaza de Mayo donde meses antes se manifestaron los miembros del Centro de Movilizados y Convocados. Durante estos días se estableció un contrapunto entre el referente de los Bajo bandera, Juan Carlos Medina, y el de la Asociación Regional Argentina de Convocados y Movilizados de Malvinas, Oscar Insaurralde, ya que el primero acusó al segundo de "vender la causa” a cambio de un puesto de trabajo. A su vez, este último denunció al bloque de la UCR (quienes votaron por la aprobación de la Ley) de poner a los movilizados “contra el gobierno y hacernos pelear entre nosotros mismos (...) no estoy en contra de la Ley (pero) la Alianza sigue aprobando leyes en contra de la economía provincial”트. Días posteriores, la Asociación “Soldados bajo bandera- conflicto Malvinas Argentinas” y la Asociación “Centro de Movilizados por Malvinas Sudoeste Chaqueño” llevaron a cabo movilizaciones con intentos de corte del puente interprovincial y marchas a pie por la Autovía Nicolás Avellaneda, a las afueras de la capital chaqueña. Estas movilizaciones se desactivaron tras la creación de la Mesa Provincial de Trabajo por los Movilizados, Convocados y Bajo Bandera. Como vimos, en agosto, el Centro de Movilizados y Convocados presentó una serie de reclamos ante el veto, que fueron acompañados por la Mesa.

Luego del decreto de reglamentación de la Ley 6.347(Decreto 1648/10), Barrientos, Insaurralde y Medina estuvieron juntos en el anuncio oficial del 8 de septiembre de 2010. Sin embargo, días después, la Asociación de Soldados Bajo Bandera envió una solicitada a un diario local afirmando que

el beneficio contempla a todos y no como dice el compañero Daniel Barrientos que solamente es para los 900 soldados que fueron al sur (...). Nos sentimos discriminados por este compañero y no es la primera vez que nos sentimos así, habla solamente para la gente que estuvieron en el Sur por el conflicto con Gran Bretaña (sic) y en realidad la ley 6347 que salió el 21 de octubre del año pasado en ningún lugar habla de paralelos o porcentaje y habla para soldados conscriptos chaqueños $\frac{67}{}$.

Pese a esta aclaración, efectivamente la Ley 6.347 reglamentada en 2010 sólo benefició a los movilizados al sur del paralelo $42^{\circ}$ por lo cual, y tras reclamos en simultáneo los Bajo Bandera y la Asociación Regional Noroeste de Convocados y Movilizados, más la presión de la C.M.C.M.CH para sostener el beneficio para los movilizados al sur, se lograron en 2012 las leyes 6990 y 6991 que diferencia los tipos de pensiones y sus características.

\section{Conclusiones}

Como pudimos apreciar, hay una serie de aspectos que marcan una regularidad entre los casos que abordamos. En primer término, la conformación de asociaciones que representan a un sector 
específico como modo de conseguir logros, luego las presentaciones de proyectos de ley en las legislaturas locales y distintas acciones de presión en el espacio público. Trataremos de marcar algunas cuestiones diferenciales de ambos procesos y que pueden ayudar a explicar sus resultados y abrir el campo de visión sobre el problema de los movilizados.

En el caso correntino pudimos ver que el conflicto desatado se llevó a cabo en un terreno reducido: una asociación de movilizados frente a una -fuerte, con trayectoria- de excombatientes. Además, la base del pedido original fue el reconocimiento como veterano de guerra sin delimitar aspectos diferenciales -en los marcos legales- con los demás partícipes de la guerra. En el caso chaqueño, el proceso -si bien con antecedentes y obviamente presiones previas- inició con un llamado del Ejecutivo y dos decretos de reconocimiento, cuestión que no sucedió en Corrientes (donde el decreto de reconocimiento desactivó una medida de fuerza de 42 meses). Asimismo, el número de movimientos de movilizados implicados fue distinto, con mayor grado de dispersión en la demanda y sus sostenes de reconocimiento: bajo bandera, convocados, movilizados al sur. Si bien se presentó un solo proyecto (a diferencia de los tres correntinos, todos archivados), el derrotero del expediente hasta su resolución mostró la estrategia de diferenciación respecto a los beneficios de excombatientes y veteranos. A la par, el movimiento de expediente y comisiones hizo visible el uso del tema como disputa entre bloques, cuestión que no sucedió en los tratamientos correntinos. Tenemos que agregar que, salvo al inicio y con un fuerte apoyo de movimientos correntinos, los excombatientes chaqueños no tuvieron un papel preponderante de presión a los legisladores para frenar el pedido "movilizado", lo cual puede ser explicado por su falta de unidad y nivel de conflicto interno. Como vimos, el CESCEM correntino, en cambio, encabezó la disputa con los movilizados de su provincia y también lo hizo en el Chaco.

En síntesis. La primera de las dimensiones abordadas nos mostró un marco similar respecto a las movilizaciones previas, no así una regularidad en las marcas de identidad. En Corrientes se planteó una igualación en parámetros de reconocimiento (veterano-excombatiente), mientras que en Chaco esta presentación fue más moderada. En el plano estratégico-legal, los expedientes y debates internos mostraron que en Chaco se cruzaron disputas de bloques en la bicameral y apoyo de movimientos a cada bloque, lo que significó que el grado de tensión fue mayor. En Corrientes, en cambio, el plano del debate no fue escenario de disputas interpartidarias y primó -entendemos- el capital acumulado del CESCEM local. Por último, la dimensión estratégica-política nos dejó ver que en Chaco la dispersión en el reclamo creó las condiciones para que durante todo el proceso se posicione una voz distinta al frente de las disputas y además forzó al Ejecutivo provincial a establecer acuerdos constantes con grupos distintos. En cierta manera, pese a que el C.M.C.M.CH tuvo mayor peso, la toma de palabra y convocatoria a referentes de las diversas asociaciones (con sus disputas internas y sus marcos de referencia disímiles) generó mayores locutores sobre el mismo problema, mientras que en Corrientes el largo acampe del único movimiento en disputa no tuvo efectos políticos concretos, salvo el decreto de reconocimiento que lejos estuvo de los objetivos planteados. Como podemos ver, el problema movilizado es una muestra siempre latente de que la guerra de Malvinas no es un episodio cerrado en la democracia argentina, y por supuesto que tampoco lo es como objeto de indagación para las ciencias sociales. 


\section{Notas}

1 En adelante usaremos el término movilizados en cursiva para referirnos al problema de los ex soldados no reconocidos como veteranos de guerra.

$\underline{2}$ En Argentina el término veterano o excombatiente ha diferenciado históricamente a los ex soldados que participaron en acciones bélicas durante el conflicto bélico por Malvinas. En general los movimientos que se reconocen como veteranos aceptan la inclusión de los oficiales y sub oficiales en la memoria de la guerra, mientras que los que se definen como excombatientes resaltan su lugar de ex conscripto. De todas formas esta diferencia no es homogénea, no todos los movimientos las manifiestan con esa claridad y se han ido modificando a lo largo del tiempo. Ver (Guber, 2004; Lorenz, 2012).

$\underline{3}$ Es decir todos aquellos convocados a los regimientos locales o movilizados a las bases del sur del país, pero que no entraron en acciones efectivas de combate ni cruzaron a las Islas Malvinas. El término implica estar bajo las órdenes de las Fuerzas Armadas por cierto período. La condición "bajo bandera” alude principalmente a la situación que atraviesan los civiles tanto en situación de guerra como en el servicio militar.

4 Para ver algunas posiciones de los excombatientes respecto a los movilizados ver Guber (2007); Rodríguez (2011) o lo trabajado en un artículo de mi autoría en Chao (2015).

$\underline{5}$ Ver también la interesante discusión sobre la noción de identidad política en Aboy Carlés (2001)

$\underline{6}$ Diario La opinión. “Se realizará el $1^{\circ}$ Congreso de Veteranos de las Malvinas”. 6 de febrero de 2007. Recuperado de http://www.laopinion-rafaela.com.ar/opinion/2007/02/06/c720636.htm [fecha de consulta 02 de julio de 2015].

Z Entre los que destacamos: Exp. 3030-D-05 (José Mongeló - PJ), que buscaba la inclusión en los beneficios de la ley de todos aquellos ex soldados conscriptos que se encontraban bajo bandera durante el transcurso del conflicto bélico de Malvinas y aquellos que hubieren sido convocados a participar en el conflicto argentino británico por las Malvinas mediante la respectiva cédula de llamada; Exp. 6958-D-2006 (Guillermo Baigorri - Vida y Compromiso), reconocimiento como excombatiente y/o veterano a todos los que participaron en el conflicto; Exp. 1282-D-2007 (Elsa Quiroz y Marcela Rodriguez - Coalición Cívica/Ari) por modificación del art. 1 de la 23.109 para incluir a los bajo bandera; Exp. 563-S-07 (Miguel Ángel Pichetto y Jorge Capitanich - PJ), pensión a favor de los ex soldados conscriptos bajo bandera entre el 2 de abril y 14 de junio de 1982; Exp. 4048-D-2010 (Silvia Vázquez - FORJA), de reconocimiento histórico a ciudadanos bajo bandera de la “Causa Malvinas”, clases 1961-1962-1963.

$\underline{8}$ Sobre el problema de la experiencia bélica y su relación con la construcción identitaria pueden citarse, entre otros, a autores como Rodríguez (2014) y la reciente de obra de Guber (2016). Los relatos y reconfiguraciones en posguerra, se entremezclan con los recuerdos de tristezas, alegrías, momentos cotidianos de las batallas o, en este caso, de la espera en continente. Si bien no está trabajado en su especificidad en este texto, es claro que este tipo de construcción experiencial juega en lo identitario más allá de los ejemplos mencionados.

$\underline{9}$ La veracidad de esta historia excede las pretensiones de este trabajo, el ejemplo nos interesa tan 
sólo por su funcionamiento como argumento en el reclamo.

10 Protocolo I adicional a los Convenios de Ginebra. Comité Internacional de la Cruz Roja. Ver https://www.icrc.org/spa/resources/documents/misc/protocolo-i.htm

11 Documento Ministerio de Defensa. “Conflicto del Atlántico Sur - Malvinas”.

12 El 28 de mayo de 2001 -según su estatuto- inició sus reuniones regulares la Asociación "Veteranos del Teatro de Operaciones del Atlántico Sur Clase 1962” de la provincia de Corrientes, que logró la Personería Jurídica el 27 de diciembre de ese mismo año. El espacio nuclea a ex soldados bajo bandera de la clase 1962, y a todos aquellos ex soldados que acrediten haber estado bajo bandera, y hayan sido incorporados con dicha clase.

13 Diario Época. "Reclamo de Veteranos". 28 de abril de 2005. Recuperado de http://diarioepoca.com/74144/Reclamo-de-Veteranos/. [fecha de consulta 13 de noviembre de 2014]

14 Diario La República. “Integrantes del Toas cortaron el Puente cerca de ocho horas”. 26 de noviembre de 2005. Recuperado de http://www.diariolarepublica.com.ar/notix/noticia.php?

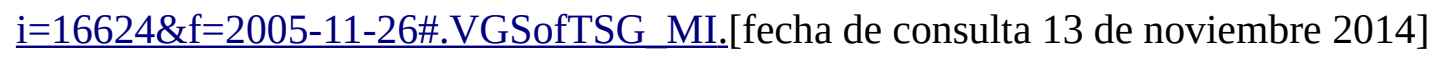

15 Diario Chaco día por día. “Movilizado de Malvinas reclamó subido a una antena”. 5 de diciembre de 2006. Recuperado de http://chacodiapordia.com/noticia/4418/movilizado-demalvinas-reclamo-subido-a-una-antena. [fecha de consulta 29 de enero de 2016]

16 Diario Chaco día por día. “Nilda Garré recibirá este viernes a movilizados de guerra del Chaco”. 20 de diciembre de 2006. Recuperado de_http://chacodiapordia.com/noticia/2169/nilda-garrerecibira-este-viernes-a-movilizados-de-guerra-del-chaco. [fecha de consulta 29 de enero de 2016].

17 En 1990 inician una serie de reuniones un grupo de convocados y movilizados al sur del paralelo $42^{\circ}$.En 1995 obtienen la personería jurídica bajo el nombre de Centro de Movilizados y convocados de Malvinas. En 2004 eligen como presidente a Daniel Barrientos e inician los primero intentos de proyecto de ley para obtener beneficios y reconocimiento oficial (entrevista personal a Daniel Barrientos).

$\underline{18}$ Diario El Litoral. “Pedido de exsoldados movilizados”. 10 de noviembre de 2007.

19 Integraron la comisión fiscalizadora Oscar Insaurralde (presidente de la Asociación Región Noroeste Argentino de Convocados y Movilizados por Malvinas, grupo que se desprende de la C.M.C.M.CH pero que también abarca a movilizados al sur del paralelo 42º , Juan Carlos Medina (presidente de la Asociación Soldados bajo bandera- conflicto Malvinas Argentinas, donde participan todos aquellos ciudadanos "bajo bandera” entre el 2 de abril y el 14 de junio de 1982), Vicente Gauna (representante de los "bajo bandera” en El Impenetrable), Rolando Mayol (representante "bajo bandera” de la Asociación Sudoeste Chaqueño), y Juan Carlos Ramírez (representante del Centro de Movilizados y convocados por Malvinas). Diario Norte. "Censarán a convocados y movilizados por Malvinas". 3 de febrero de 2008. Recuperado de http://www.diarionorte.com/article/7603/censaran-a-convocados-y-movilizados-por-malvinas [fecha de consulta 20 de enero de 2016].

$\underline{20}$ Decreto 1155/08. Archivo de la Legislatura de la provincia de Chaco. 
$\underline{21}$ Siglas del Partido Nuevo, liderado por el ex gobernador Raúl Rolando “Tato” Romero Feris.

$\underline{22}$ Expediente 3544/06. Archivo de la Legislatura de la provincia de Corrientes.

$\underline{23}$ Que establece el beneficio y monto que deben cobrar los excombatientes.

$\underline{24}$ Expediente 3544/06. Archivo de la Legislatura de la provincia de Corrientes.

$\underline{25}$ Expediente 3777/07. Archivo de la Legislatura de la provincia de Corrientes.

$\underline{26}$ Podemos atribuir cierta disposición estratégica a este ocultamiento más allá de la posición pública de definirse como veteranos.

$\underline{27}$ Es necesario remarcar que en el tratamiento y la media sanción del proyecto, se quitó el término TOAS al encuadre de los beneficiarios.

$\underline{28}$ Diario Época. “La presión de ex combatientes trabó la pensión para movilizados”. 28 de mayo de 2008. Recuperado de http://diarioepoca.com/170561/La-presion-de-ex-combatientes-trabo-lapension-para-movilizados/ [fecha de consulta 20 de noviembre de 2014]

$\underline{29}$ Según su sitio oficial, el Centro de Ex Soldados Combatientes en Malvinas de Corrientes “comienza a fines del año 1982 es decir a unos meses de finalizar el conflicto bélico”, no obstante, la primera acta de reunión está fechada el 21 de diciembre de 1984, donde se nombró a Antonio Millán y Orlando Pascua como primer presidente y secretario respectivamente. Sus primeros objetivos fueron constituirse como un espacio susceptible de ser interlocutor a nivel institucional. Recuperado de http://www.cescem.org.ar/institucional/quienes somos.html. [fecha de consulta 02 de julio de 2015]

$\underline{30}$ Armando Aquino Britos (UCR) es un personaje clave en esta disputa por varias cuestiones. No sólo por ser excombatiente de Malvinas sino además porque fue el interlocutor (cuando era Fiscal de Estado en 2002) del gobierno de Ricardo Colombi (UCR) durante las disputas con el CESCEM por la obtención de la ley 5570/03 (pensión a excombatientes de Malvinas correntinos). Como legislador y presidente de la Comisión de Asuntos Constitucionales (2007 - 2011) tuvo, como veremos, un papel activo en “cajonear” los proyectos sobre movilizados.

$\underline{31}$ Esta Federación estuvo ligada desde su nacimiento a la Asociación “2 de abril” y posterior Federación de Veteranos de Guerra de la República Argentina quienes apoyaron a los sectores castrense dentro de la memoria de la guerra (Lorenz, 2012).

$\underline{32}$ Expediente 3777/07. Archivo de la Legislatura de la provincia de Corrientes.

33 Expediente 4776/09. Archivo de la Legislatura de la provincia de Corrientes.

34 Expediente 4776/09. Archivo de la Legislatura de la provincia de Corrientes

$\underline{35}$ El 10 de diciembre de 2009 inicia su segundo mandato el gobernador Ricardo Colombi, tras derrotar en segunda vuelta a su primo Arturo Colombi.

$\underline{36}$ Decreto provincial 1350/10. Archivo de la Legislatura de la provincia de Corrientes

37 Expediente 4776/09. Archivo de la Legislatura de la provincia de Corrientes

$\underline{38}$ Trasciende las pretensiones de este trabajo elaborar las redes de vinculación entre los centros y 
asociaciones con los partidos políticos, sobre todo porque entendemos que a nivel estratégico estas fueron modificándose a lo largo del tiempo. Como ejemplo de esta cuestión podemos mencionar los tres proyectos de ley presentados por los TOAS C/62 de Corrientes con diferentes legisladores: el primero con Bralliard Poccard y Costa (PANU); el segundo con Abib (PJ, aliado al gobierno provincial); y finalmente Snihur, Anderson y Díaz (PJ) (éstos últimos, únicos opositores). En el caso chaqueño, el acercamiento a la UCR -en palabras de Barrientos (entrevista personal)- tiene que ver con la apertura de este partido al problema movilizado al constituirse como oposición en 2007, relación que se modificó según el mismo entrevistado una vez lograda la reglamentación de la ley.

39 Expediente 708/08. Archivo de la Legislatura de la provincia de Chaco.

$\underline{40}$ Diario Norte. “La Legislatura convoca a soldados movilizados”. 4 de mayo de 2008.

41 Expediente 708/08. Archivo de la Legislatura de la provincia de Chaco.

42 Diario Chaco día por día. “Pensión graciable y vitalicia para Movilizados de Malvinas”. 28 de mayo de 2009. Recuperado de http://www.chacodiapordia.com/noticia/30223/pension-graciable-yvitalicia-para-movilizados-de-malvinas. [fecha de consulta 29 de enero de 2016].

43 Expediente 708/08. Archivo de la Legislatura de la provincia de Chaco.

44 Leyes 6347, 6816, 6848, 6884, 6990, 6991. Archivo de la Legislatura de la provincia de Chaco.

45 Diario Época. “Ex combatientes rechazan una ley “global”. 08 de octubre de 2006. Recuperado de $\quad$ http://diarioepoca.com/118788/Ex-combatientes-rechazan-una-ley-and8220globaland8221/ [fecha de consulta 19 de noviembre de 2014].

$\underline{46}$ Con esta expresión nos referimos a la discusión planteada por el TOAS C/62 respecto a ubicar a la guerra de Malvinas en el gran concierto de conflictos bélicos internaciones, mientras que, a nuestro entender, los excombatientes marcan todo el tiempo las cuestiones específicas de la guerra que vivieron.

47 Diario La República. "Enérgico reclamo de los ex combatientes”. 19 de octubre de 2006. Recuperado de http://www.diariolarepublica.com.ar/notix/noticia.php?i=111217\&f=2006-1019\#.VG3pnjSG MI [fecha de consulta 20 de noviembre de 2014].

48 Diario la República. "Las heridas abiertas que la guerra de Malvinas dejó”. 15 de noviembre de 2006. Recuperado de http://www.diariolarepublica.com.ar/notix/noticia.php?i=113268\&f=2006-1115\#.VEkP5md5PMI [fecha de consulta 23 de octubre de 2014].

49 Diario La Provincia Digital. “Avanza en Diputados la ley para los integrantes del T.O.A.S”. 27 de mayo de 2007. Disponible en http://www.laprovinciadigital.com.ar/notix/noticia.php?i=20291 [fecha de consulta 19 de noviembre de 2014].

$\underline{50}$ Diario La República. “Mañana ex combatientes protestarán contra subsidio para movilizados”. 27 de mayo de 2008. Recuperado de http://www.diariolarepublica.com.ar/notix/noticia.php? $\underline{\mathrm{i}=143798 \& \mathrm{f}=2008-05-27 \# . V E k V r G d 5 P M I}$ [fecha de consulta 23 de octubre de 2014].

$\underline{51}$ Diario Corrientes On Line. "Buscan crear fábrica de veteranos de guerra". 28 de mayo de 2008. Recuperado de http://www.corrientesonline.com/notix2/noticia/20634 buscan-crear-fabrica-de- 
veteranos-de-guerra--.htm [fecha de consulta 19 de noviembre de 2014].

$\underline{52}$ Corrientes Ya. "Veteranos del TOAS celebran el reconocimiento histórico y moral otorgado por el Gobernador Colombi”. 30 de marzo de 2010. Recuperado de http://www.corrientesya.info/index.php?option=com content\&view=article\&id=12892:el-toascelebra-el-reconocimiento-historico-y-moral-del-gobernador-colombi\&catid=449\&Itemid=466 [fecha de consulta 23 de octubre de 2014].

53 Diario digital Espacio de Noticias. "Reconocimiento histórico y moral a los que participaron en la gesta de Malvinas”. 31 de marzo de 2010. Recuperado de http://www.espaciodenoticias.com.ar/vernota.asp?id noticia=3615 [fecha de consulta 20 de noviembre de 2014].

54 Diario digital Corrientes Online. "Veteranos de Guerra levantaron la carpa instalada frente a Casa de Gobierno”. 30 de marzo de 2010. Recuperado de http://www.corrientesonline.com/notix2/noticia/38854 veteranos-de-guerra-levantaron-la-carpainstalada-frente-a-casa-de-gobierno.htm [fecha de consulta 23 de octubre de 2014].

$\underline{55}$ Radio Sudamericana. "Es una falta de respeto a los compañeros que quedaron en Malvinas". 01 de abril de 2014.20 Recuperado de http://www.cescem.org.ar/informacion/noticias/2010/pag10 013.html [fecha de consulta 23 de octubre de 2014].

$\underline{6}$ Patrulla de Alto riesgo, unidad de choque de la Policía de la Provincia de Corrientes.

57 Diario La República. “Incidentes en la Legislatura por el reconocimiento a Movilizados”. 22 de abril de 2010. Recuperado de http://www.diariolarepublica.com.ar/notix/noticia.php?

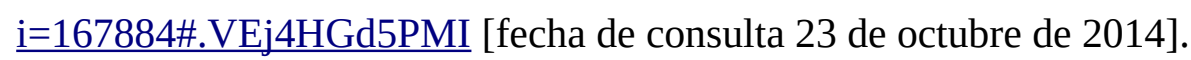

58 “En Malvinas demostramos que podemos hacer frente a los poderosos”. Entrevista a excombatiente Luis Garcilazo. Recuperado de http://cescemchaco.blogspot.com.ar/2012/01/bim-2garcilazo-luis.html. [fecha de consulta 22 de febrero de 2016].

59 Diario de La Región. “Marcha en contra de la pensión para convocados y movilizados”. 6 de mayo de 2008. [fecha de consulta 20 de enero de 2016].

60 Sitio oficial CESCEM Corrientes. "Forcejeos, manotazos, empujones, amenazas de muerte y disparos de parte de movilizados tratando de impedir el ingreso de los ex combatientes a la legislatura chaqueña”. 16 de julio de 2008. Recuperado de http://www.cescem.org.ar/informacion/noticias/2008/pag08 068.html. [fecha de consulta 23 de octubre de 2014].

61 Diario chaco día por día. "Ex Combatientes repudian a diputados de la Alianza”. 15 de julio de 2008. Recuperado de_http://www.chacodiapordia.com/noticia/19491/ex-combatientes-repudian-adiputados-de-la-alianza. [fecha de consulta 29 de enero de 2016].

62 Diario Norte. "El consejo provincial de Veteranos de Guerra pide a funcionarios que obren con grandeza”. 29 de julio de 2008. Recuperado de http://www.diarionorte.com/article/16779/elconsejo-provincial-de-veteranos-de-guerra-pide-a-funcionarios-que-obren-con-grandeza. [fecha de 
consulta 29 de enero de 2016].

63 Diario Chaco día por día. "Movilizados de Malvinas levantaron el acampe de la Plaza”. 20 de septiembre de 2008. Recuperado de http://www.chacodiapordia.com/noticia/21549/movilizados-demalvinas-levantaron-el-acampe-de-la-plaza. [fecha de consulta 29 de enero de 2016].

64 Diario Norte. “Mongeló recibió a movilizados de Malvinas que acampan en la plaza”. 15 de septiembre de 2008. Recuperado de http://www.diarionorte.com/article/19034/mongelo-recibio-amovilizados-de-malvinas-que-acampan-en-la-plaza. [fecha de consulta 29 de enero de 2016].

65 Diario chaco día por día. "Movilizados de Malvinas se encadenaron en la Casa de Gobierno”. 1 de abril de 2009. Recuperado de http://www.chacodiapordia.com/noticia/28177/movilizados-demalvinas-se-encadenaron-en-la-casa-de-gobierno. [fecha de consulta 29 de enero de 2009].

66 Diario chaco día por día. “Acusan a la Alianza de enfrentar a soldados con el gobierno”. 17 de junio de 2009. Recuperado de http://chacodiapordia.com/noticia/30971/acusan-a-la-alianza-deenfrentar-a-soldados-con-el-gobierno. [fecha de consulta 29 de enero de 2016].

67 Diario Norte. “Soldados Bajo Bandera aclara que la pensión es para todos”. 19 de septiembre de 2010. p. 10. [fecha de consulta 20 de enero de 2016].

\section{Referencias bibliográficas}

Aboy Carlés, G. (2001). Las dos fronteras de la democracia argentina. La reformulación de las identidades políticas de Alfonsín y Menem. Rosario: Homo Sapiens.

Bourdieu, P. y Wacquant, L (2014). Respuestas. Por una antropología reflexiva. Buenos Aires: Siglo XXI.

Bourdieu, P. (2013). Las estrategias de la reproducción social. Buenos Aires: Siglo XXI.

Chao, D. (2015). ¿Quién es excombatiente? El acampe de los "movilizados" de Malvinas en la ciudad de Corrientes (2006 - 2010). Revista Paginas (Rosario),Vol.7, N¹3, pp. 33 - 53. Recuperado de http://revistapaginas.unr.edu.ar/index.php/RevPaginas/article/view/4

Guber, R. (2004). De chicos a veteranos. Memorias argentinas de la guerra de Malvinas. Buenos Aires: Editorial Antropofagia.

Guber, R. (2007). Los Veteranos truchos de Malvinas: la autenticidad como competencia metacomunicativa en las identidades del trabajo de campo. Revista Universitas Humanística

(Bogotá), $\quad \mathrm{N}^{\circ}$ 63, $\quad$ pp. 49-68. $\quad$ Recuperado de http://revistas.javeriana.edu.co/index.php/univhumanistica/article/view/2231

Guber, R. (2016). Experiencia de Halcón. Buenos Aires: Sudamericana.

Iglesias, E. (2008). Política y Protesta. Visiones comparadas sobre la acción colectiva. En Fernández, A. y Lesgart, C. (comp.) La democracia en América latina. Partidos Políticos y Movimientos Sociales (pp.149-170). Rosario: Homo Sapiens. 
Lorenz, F. (2012). Las guerras por Malvinas. Buenos Aires:Edhasa.

Muñoz, J. (2005). Ataquen Río Grande. Operación Mikado. Comodoro Rivadavia: Instituto de Publicaciones Navales.

Rodríguez, A. (2010). De veteranos “verdaderos” y “truchos”. Análisis de las definiciones de "excombatiente/veterano de guerra" de los miembros del Apostadero Naval Malvinas en el Conflicto del Atlántico Sur. Anuario del Centro de Estudios Históricos "Prof. Carlos S. A. Segreti” (Córdoba),Año 10, $\quad \mathrm{N}^{\circ} \quad 10, \quad$ pp. 303-323. Recuperado de http://cehsegreti.org.ar/archivos/FILE 00000368 1411760997.pdf

Rodríguez, B. (2014). Entre la guerra y la paz: la posguerra de los excombatientes del Apostadero Naval Malvinas. Experiencias, identidades, memorias (Tesis doctoral inédita) Facultad de Humanidades y Ciencias de la Educación. UNLP.

\section{Fuentes oficiales}

Expediente 3544/06. Archivo de la Legislatura de la provincia de Corrientes

Expediente 3777/07. Archivo de la Legislatura de la provincia de Corrientes

Expediente 4776/09. Archivo de la Legislatura de la provincia de Corrientes

Expediente 708/08. Archivo de la Legislatura de la provincia de Chaco.

Ley 6347. Archivo de la Legislatura de la provincia de Chaco.

Ley 6816. Archivo de la Legislatura de la provincia de Chaco.

Ley 6848. Archivo de la Legislatura de la provincia de Chaco.

Ley 6884. Archivo de la Legislatura de la provincia de Chaco.

Ley 6990. Archivo de la Legislatura de la provincia de Chaco.

Ley 6991. Archivo de la Legislatura de la provincia de Chaco.

Decreto 355/08.Archivo de la Legislatura de la provincia de Chaco.

Decreto 1155/08. Archivo de la Legislatura de la provincia de Chaco.

Decreto 1648/08. Archivo de la Legislatura de la provincia de Chaco.

Expediente 3030-D/05. Archivo HCD de la Nación Argentina.

Expediente 6958-D/06. Archivo HCD de la Nación Argentina.

Expediente 1282-D/07. Archivo HCD de la Nación Argentina.

Expediente 563-S/07. Archivo HCS de la Nación Argentina.

Expediente 4048-D/10. Archivo HCD de la Nación Argentina.

Fallo Corte Suprema. Causa ,Arfinetti, Víctor Hugo c-Estado Nacional 
Fallo Corte Suprema. Gerez, C. c/Estado Nacional.

\section{Informes}

Conflicto del Atlántico Sur - Malvinas. Documento Ministerio de Defensa.

Protocolo I adicional a los Convenios de Ginebra de 1949.

\section{Periódicos impresos.}

Diario El Litoral. Corrientes. 2005 - 2010. Hemeroteca del Archivo General de la Provincia de Corrientes.

Diario Época. Corrientes. 2005 - 2010. Hemeroteca del Archivo General de la Provincia de Corrientes

Diario Norte. 2008-2011. Chaco. Archivo Diario Norte.

Diario de La Región. Chaco. Archivo Diario de La Región.

\section{Periódicos digitales.}

Diario Clarín. http://www.clarin.com

Diario La Opinión de Rafaela. http://www.laopinion-rafaela.com.ar

Diario Época. Corrientes. http://diarioepoca.com

Diario La República. Corrientes. http://www.diariolarepublica.com.ar

Diario digital La Provincia Digital. Corrientes. http://www.laprovinciadigital.com.ar

Diario digital Corrientes Online. Corrientes. http://www.corrientesonline.com

Diario digital Nordeste al día. Corrientes. http://www.nordestealdia.com

Diario digital Corrientes ya. Corrientes. http://www.corrientesya.info.com

Diario digital Espacio de noticias. Corrientes. http://www.espaciodenoticias.com.ar

Diario digital Tres Líneas. Corrientes. http://www.treslineas.com.ar

Diario Chaco día por día. Chaco.http://chacodiapordia.com

Diario Norte. Chaco. http://www.diarionorte.com 